\title{
ANFIS Modeling For a Water-Methanol System in a Spiral Plate Heat Exchanger
}

\author{
A.Mohamed Shabiulla ${ }^{1}$ and S.Sivaprakasam ${ }^{2}$

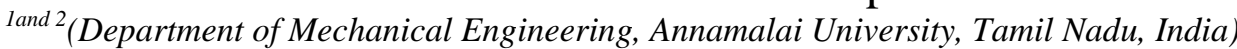

\begin{abstract}
In this paper, an experimental investigation of Water-Methanol system in a Spiral plate Heat Exchanger (SHE) is presented. Experiments have been conducted by varying the mass flow rate of cold fluid (Methanol), the mass flow rate of hot fluid (Water) and inlet temperature of the hot fluid, by keeping inlet temperature of the cold fluid constant. The effects of relevant parameters on the performance of spiral plate heat exchanger are studied. Also, in this paper, an attempt is made to propose Adaptive Network based Fuzzy Inference System (ANFIS) and Artificial Neural Network (ANN) models for the analysis of SHE. The data required to train the models are obtained from the experimental data based on Response Surface Methodology (RSM). The ANN models are developed using Back Propagation Network (BPN) algorithm, incorporating Levenberg-Marquardt (L-M) training method. The ANFIS models are developed based on advanced neuralfuzzy technology. The ANFIS model possesses the robustness of fuzzy system, the learning ability of neural networks and can adapt to various situations. The accuracy of the trained networks are verified according to their ability to predict unseen data by minimizing root mean square error (RMSE), average percentage error $(A P E)$ and correlation coefficient $\left(\% R^{2}\right)$ value. The prediction of the parameters can be obtained without using charts and complicated equations.

The data obtained from ANFIS and ANN models for overall heat transfer coefficient $(U)$ and pumping power (Wp) are compared with those of experimental data. It is observed that the accuracy between the ANFIS model's predictions, $N N$ model's predictions and experimental values are achieved with minimum \% error, APE, RMSE and Correlation coefficient $\left(\% R^{2}\right)$. Also it is proved that ANFIS models give better performance than ANN models.
\end{abstract}

Keywords: Spiral plate Heat Exchanger (SHE); Overall heat transfer coefficient (U); Pumping Power $\left(W_{p}\right)$; Artificial Neural Networks (ANNs) and Adaptive Network based Fuzzy Inference System (ANFIS) models .

\section{Introduction}

Heat exchangers are devices which are used to enhance or facilitate the flow of heat. Their application has a wide coverage from industry to commerce. They are widely used in space heating, refrigeration, air conditioning, power plants, chemical plants, petrochemical plants, petroleum refineries and natural gas processing. One common example of a heat exchanger is the radiator in a car, in which a hot engine-cooling fluid, like antifreeze, transfers heat to air flowing through the radiator [1].

Compared to shell-and-tube heat exchangers, spiral plate heat exchangers are characterized by their large heat transfer surface area per unit volume, resulting in reduced space, weight, support structure, energy requirements and cost, as well as improved process design, plant layout and processing. Spiral plate heat exchangers have the distinct advantages over other plate type heat exchangers in the aspect that they are self cleaning equipments with low fouling tendencies, easily accessible for inspection or mechanical cleaning. They are best suited to handle slurries and viscous liquids. The use of spiral heat exchangers is not limited to liquidliquid services. Variations in the basic design of SHE makes it suitable for Liquid-Vapour or Liquid-Gas services .

Few literatures have reported about Spiral Heat Exchanger [1 to 4]. Rajavel et al [2 and 3] have conducted experiments on different process fluids to study the performance of a spiral heat exchanger and developed correlations for different fluid systems. Martin [1] numerically studied the heat transfer and pressure drop characteristics of a spiral plate heat exchanger. The apparatus used in the investigations had a cross section of $5 \times 300 \mathrm{~mm}^{2}$, number of turns $\mathrm{n}=8.5$, core diameter of $250 \mathrm{~mm}$ and outer diameter of $495 \mathrm{~mm}$.

More number of experimental data are required to develop correlations to predict the parameters such as $\mathrm{U}$ and $\mathrm{W}_{\mathrm{p}}$ etc. using mathematical methods like regression analysis. The Artificial Neural Network (ANN) modeling technique has the capability to predict the unseen data by using a reasonable set of experimental data resulting in more speed and accuracy. Recently, many researchers have addressed about ANN modeling to heat exchangers [5 and 6].However, not many addressed about ANN modeling for Spiral plate Heat Exchangers (SHEs). Hence, an attempt is made in this work, to study the experimental behaviour of SHEs and model the SHE's characteristics using ANN technique. In order to improve the performance of ANN further, an ANFIS model is proposed for SHE. Presently, much interest is focused in the field of neuro-fuzzy system because of its 
cost effective methodology of modeling and its application to model any non-linear systems. An ANFIS model combining the robustness of fuzzy systems and the learning ability of neural networks (NNs) offers a more powerful tool for modeling [7-9].Hence in this work, a new attempt is made to model the performances of SHE using ANFIS technique.

\section{Experimental Set-up}

The experimental heat exchanger set-up is shown in Fig.1. The heat exchanger was constructed using 316 stainless steel plates. The spiral plate heat exchanger had a width of $304 \mathrm{~mm}$ and a plate thickness of $1 \mathrm{~mm}$. The total heat transfer area is $2.24 \mathrm{~m}^{2}$. The end connections are shown in Fig.1. The radius of curvature (measured from the centre) of the plate is $177.4 \mathrm{~mm}$ and the gap between the plates is $5 \mathrm{~mm}$. The dimensions of the spiral plate heat exchanger are tabulated in TABLE I.

The heat transfer and flow characteristics of water- methanol system were tested in a spiral plate heat exchanger as shown in Fig.1. Water was used as the hot fluid. The hot fluid inlet pipe was connected to the central core of the spiral heat exchanger and the outlet pipe was taken from the periphery of the heat exchanger. Hot fluid was heated by pumping steam from the boiler to a temperature of about $60^{\circ} \mathrm{C}$ to $80^{\circ} \mathrm{C}$. The hot fluid was pumped to the heat exchanger by using a fractional horse power $(0.367 \mathrm{~kW})$ pump. Methanol was used as the cold fluid. The cold fluid inlet pipe was connected to the periphery of the exchanger and the outlet was taken from the centre of the heat exchanger. The cold fluid was supplied at room temperature from a tank and was pumped to the heat exchanger using a fractional horse power $(0.367 \mathrm{~kW})$ pump. The inlet cold fluid flow rate and the inlet hot fluid flow rate were varied using the control valves $\mathrm{V}_{1}$ and $\mathrm{V}_{2}$, respectively. Hot and cold fluid flow paths of the heat exchanger are as shown in Fig.1. Thermocouples $T_{4}$ and $T_{2}$ were used to measure the outlet temperature of hot and cold fluids, respectively and $\mathrm{T}_{3}$ and $\mathrm{T}_{1}$ were used to measure the inlet temperature of hot and cold fluids, respectively. The inlet temperature of the cold fluid is kept constant. For different process conditions viz. hot fluid flow rate, cold fluid flow rate and the inlet temperature of hot fluid, the corresponding outlet temperature of hot and cold fluids were recorded. Temperature data was recorded in the span of ten seconds. The data used in the calculations were obtained after the system attained steady state. Temperature reading fluctuations were within $+/-0.15^{\circ} \mathrm{C}$. Though the type-K thermocouples had limits of error of $2.2^{\circ} \mathrm{C}$ or $0.75 \%$ when placed in a common water solution the readings at steady state were all within $+/-0.1^{\circ} \mathrm{C}$. All the thermocouples were constructed from the same roll of thermocouple wire and hence the repeatability of the temperature readings was high.

The operating ranges of different variables are given in TABLE II.The experiments were conducted by keeping the cold fluid inlet temperature at $26^{\circ} \mathrm{C}$. The experimental data were obtained by varying hot and cold fluid flow rate from 0.1 to $0.9 \mathrm{~kg} / \mathrm{s}$ for different hot fluid inlet temperatures $60^{\circ} \mathrm{C}, 70^{\circ} \mathrm{C}$ and $80^{\circ} \mathrm{C}$ based on the experimental design formulated by Response Surface Methodology (RSM) using Design Expert software [10] and [11]. The experimental results and the corresponding Overall heat transfer coefficient (U) and Pumping Power (Wp) are tabulated in TABLE III.

\subsection{Variables to be considered for investigation \\ 2.1.1 Overall heat transfer coefficient (U)}

In the case of heat exchangers, various thermal resistances in the path of heat flow from the hot fluid to the cold fluid are combined and represented as the overall heat transfer coefficient (U).The overall heat transfer coefficient is obtained from the relation:

$$
\mathrm{U}=\mathrm{Q} /(\mathrm{A} \Delta \mathrm{T})_{1 \mathrm{~m}}
$$

where $U$ is the overall heat transfer coefficient $\left(W / \mathrm{m}^{2} \mathrm{~K}\right), \mathrm{A}$ is the heat transfer area $\left(\mathrm{m}^{2}\right)$ and $\mathrm{Q}$ is the $\log$ mean temperature difference $(\mathrm{K})$.

\subsubsection{Pumping power $\left(W_{p}\right)$}

It is the power required to pump the fluid through the flow channel against the pressure drop. $\mathrm{W}_{\text {POwER }}$ is measured in Watt $(\mathrm{W})$ :

$$
\mathrm{W}_{\mathrm{P}}=\frac{\text { Volume flow rate } \mathrm{x} \text { Pressure drop }(\Delta \mathrm{P})}{\text { Density of the fluid }}
$$


TABLE I. Dimensions of the Spiral Plate Heat Exchanger

\begin{tabular}{|c|l|c|}
\hline Sl.No. & \multicolumn{1}{|c|}{ Parameter } & Dimensions \\
\hline 1 & Total heat transfer area $\left(\mathrm{m}^{2}\right)$ & 2.24 \\
\hline 2 & Plate width $(\mathrm{mm})$ & 304 \\
\hline 3 & Plate thickness $(\mathrm{mm})$ & 1 \\
\hline 4 & Plate material & 316 Stainless steel \\
\hline 5 & Plate conductivity $\left(\mathrm{W} / \mathrm{m}^{\circ} \mathrm{C}\right)$ & 15.364 \\
\hline 6 & Core diameter $(\mathrm{mm})$ & 273 \\
\hline 7 & Outer diameter $(\mathrm{mm})$ & 350 \\
\hline 8 & Channel spacing $(\mathrm{mm})$ & 5 \\
\hline
\end{tabular}

TABLE II. Experimental conditions

\begin{tabular}{|c|l|c|}
\hline Sl.No. & \multicolumn{1}{|c|}{ Variables } & Range \\
\hline 1 & Hot fluid inlet temperature & $60-80{ }^{\circ} \mathrm{C}$ \\
\hline 2 & Cold fluid inlet temperature & $26{ }^{\circ} \mathrm{C}$ \\
\hline 3 & Mass flow rate of hot fluid & $0.1-0.9 \mathrm{~kg} / \mathrm{s}$ \\
\hline 4 & Mass flow rate of cold fluid & $0.1-0.9 \mathrm{~kg} / \mathrm{s}$ \\
\hline
\end{tabular}

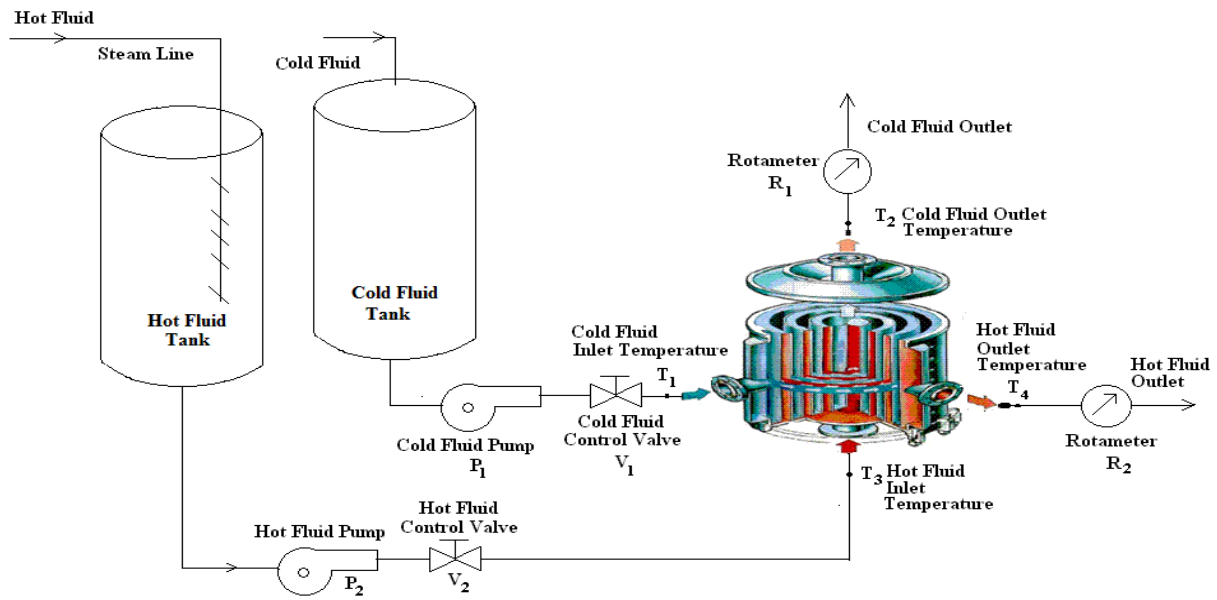

Figure 1. Schematic diagram of the SHE experimental set-up

\begin{tabular}{|c|c|c|c|c|c|}
\hline SI.No & $\begin{array}{l}\text { Cold fluid } \\
\text { flow rate } \\
\dot{\text { m }} \text { c }^{(\mathrm{kg} / \mathrm{s})}\end{array}$ & $\begin{array}{l}\text { Hot fluid } \\
\text { flow rate } \\
\dot{\mathbf{m}}_{\mathbf{h}}(\mathrm{kg} / \mathrm{s})\end{array}$ & $\begin{array}{l}\begin{array}{c}\text { Hot fluid } \\
\text { inlet } \\
\text { temperature } \\
\mathbf{T}_{\mathbf{h}, \text { in }}\left({ }^{\circ} \mathrm{C}\right)\end{array}\end{array}$ & $\begin{array}{c}\text { Overall Heat } \\
\text { Transfer } \\
\text { Coeff. } \\
\mathbf{U} \\
\left(\mathrm{W} / \mathbf{m}^{2} \mathbf{K}\right)\end{array}$ & $\begin{array}{c}\text { Pumping power } \\
\mathbf{W}_{\mathbf{p}} \\
(\mathbf{W})\end{array}$ \\
\hline 1 & 0.5 & 0.5 & 70 & 719 & 1.13 \\
\hline 2 & 0.5 & 0.5 & 70 & 719 & 1.13 \\
\hline 3 & 0.5 & 0.1 & 80 & 316 & 0.01 \\
\hline 4 & 0.5 & 0.1 & 60 & 292 & 0.02 \\
\hline 5 & 0.9 & 0.9 & 70 & 1050 & 6.01 \\
\hline 6 & 0.9 & 0.5 & 80 & 819 & 1.13 \\
\hline 7 & 0.1 & 0.5 & 60 & 397 & 1.10 \\
\hline 8 & 0.5 & 0.9 & 80 & 933 & 6.02 \\
\hline 9 & 0.1 & 0.1 & 70 & 229 & 0.02 \\
\hline 10 & 0.9 & 0.5 & 60 & 781 & 1.13 \\
\hline 11 & 0.1 & 0.5 & 80 & 411 & 1.11 \\
\hline 12 & 0.5 & 0.9 & 60 & 880 & 6.10 \\
\hline 13 & 0.9 & 0.1 & 70 & 318 & 0.01 \\
\hline 14 & 0.1 & 0.9 & 70 & 451 & 6.20 \\
\hline 15 & 0.5 & 0.5 & 70 & 719 & 1.13 \\
\hline
\end{tabular}

TABLE III. Experimental Readings for water-methanol system 


\section{Modeling of Spiral Heat Exchanger}

In this paper, an attempt is made to develop ANFIS and ANN models for $\mathrm{U}$ and $\mathrm{W}_{\mathrm{p}}$ of SHE. The data required to train the models were obtained from the experimental data as given in TABLE III, based on RSM for fifteen trials [10 and 11].

\subsection{ANN Models}

In order to find the relationship between the input and output data derived from experimental work, a more powerful method than the traditional ones are necessary. ANN is an especially efficient algorithm to approximate any function with finite number of discontinuities by learning the relationships between input and output vectors. These algorithms can learn from the experiments and also are fault tolerant in the sense that they are able to handle noisy and incomplete data. The ANNs are able to deal with non-linear problems and once trained can perform estimation and generalization rapidly. They have been used to solve complex problems that are difficult to be solved, if not impossible, by the conventional approaches, such as control, optimization, classification and so on. Specially it is desired to have the minimum difference between the predicted and observed outputs. ANNs are biological inspirations based on the various brain functionality characteristics. They are composed of many simple elements called neurons that are interconnected by links and act like axons to determine an empirical relationship between the inputs and outputs of a given system [6]. General multiple layer arrangement of a typical interconnected neural network is shown in Figure2.

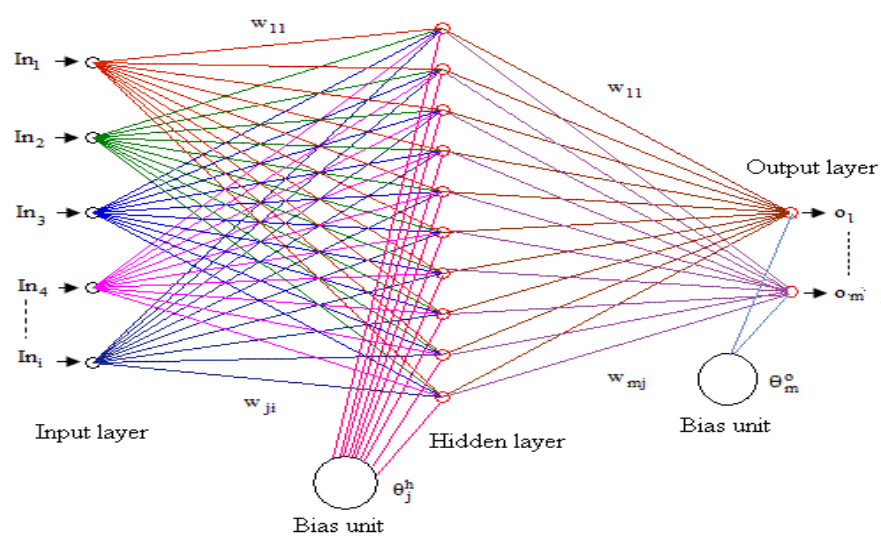

Figure 2. General neural network architecture of a neural model.

It consists of an input layer, an output layer and one hidden layer with different roles. Each connecting line has an associated weight. ANNs are trained by adjusting these input weights (connection weights), so that the calculated outputs may be approximated by the desired values.

The output from a given neuron is calculated by applying a transfer function to a weighted summation of its input to give an output, which can serve as input to other neurons as follows:

$$
\alpha_{j m}=F_{m}\left(\sum_{i=1}^{m-1} w_{i j m} \alpha_{i(m-1)}+\beta_{j m}\right)
$$

The model fitting parameters $\mathrm{w}_{\mathrm{ijm}}$ are the connection weights and $\alpha_{\mathrm{jm}}$ is the predicted output. The nonlinear activation transfer functions $\mathrm{F}_{\mathrm{m}}$ may have many different forms. The classical ones are threshold, sigmoid, Gaussian and linear function etc. The training process requires a proper set of data i.e., input $\left(\mathrm{In}_{\mathrm{i}}\right)$ and target output $\left(\mathrm{t}_{\mathrm{i}}\right)$. During training, the weights and biases of the network are iteratively adjusted to minimize the network performance function. The typical performance function that is used for training feed forward neural networks is the network Mean Squared Errors (MSE):

$$
\operatorname{MSE}=\frac{1}{N} \sum_{i=1}^{N}\left(e_{i}\right)^{2}=\frac{1}{N} \sum_{i=1}^{N}\left(t_{i}-O_{i}\right)^{2}
$$

In this paper, the back propagation learning algorithm, which is one of the most commonly used algorithms, is designed to predict the performances of SHE. The back propagation learning network is the simplest in implementation, in which, the weights and biases are updated in the direction of the negative gradient so that the performance function decreases most rapidly. There are various back propagation algorithms such as Scaled Conjugate Gradient (SCG), Levenberg-Marquardt (LM) and Resilient back Propagation (RP). LM is the fastest training algorithm for networks of moderate size and it has the memory reduction feature to be used when the training set is large. 
The neural networks learn to recognize the patterns of the data sets during the training process. Neural networks teach themselves, the patterns of data set letting the analyst to perform more interesting flexible work in a changing environment. Neural networks build informative models whereas the more conventional models fail to do so. Because of handling very complex interactions, the neural network can easily model data, which is too difficult to model traditionally (statistics or programming logic). Performance of neural networks is at least as good as classical statistical modeling and even better in most cases. The neural network built models are more reflective of the data structure and are significantly faster.

\subsubsection{Implementation of Neural Model for SHE}

The two neuro models for overall heat transfer coefficient (U) and pumping power (Wp) are developed based on $\dot{\mathrm{m}}_{\mathrm{c}}, \dot{\mathrm{m}}_{\mathrm{h}}$ and $\mathrm{T}_{\mathrm{h} \text {, in }}$. The neural network is built with three inputs, one output with one hidden layer that contains ten neurons, so the design is 3-10-1. The activation function for the hidden layer is Tansigmoidal, while for the output layer linear function is selected and they are bipolar in nature. The Levenberg Marquardt (LM) learning algorithm available in MATLAB software does the correct choice of the weight. The parameters used for training the neural model for $\mathrm{U}$ and $\mathrm{W}_{\mathrm{p}}$ are given below:

$\begin{array}{ll}\text { Input vectors } & :\left[\dot{\mathrm{m}}_{\mathrm{c}}(\mathrm{k}), \dot{\mathrm{m}}_{\mathrm{h}}(\mathrm{k}) \text { and } \mathrm{T}_{\mathrm{h}, \mathrm{in}}(\mathrm{k})\right] \\ \text { Output vector } & :[\hat{\mathrm{U}}(\mathrm{k})] \text { or }\left[\hat{\mathrm{W}}_{\mathrm{p}}(\mathrm{k})\right] \\ \text { Momentum factor } & : 0.05 \\ \text { Learning rate } & : 0.0001 \\ \text { Training parameter goal } & : 1 \mathrm{e}-4\end{array}$

The data set used for training is sufficiently rich to ensure the stable operation, since no additional learning takes place after training. During training the NN learns by fitting the input-output data pairs for $\dot{\mathrm{m}}_{\mathrm{c}}(\mathrm{k}), \dot{\mathrm{m}}_{\mathrm{h}}(\mathrm{k})$ and $\mathrm{T}_{\mathrm{h} \text {, in }}(\mathrm{k})$ Vs overall heat transfer coefficient $(\mathrm{U}), \dot{\mathrm{m}}_{\mathrm{c}}(\mathrm{k}), \dot{\mathrm{m}}_{\mathrm{h}}(\mathrm{k})$ and $\mathrm{T}_{\mathrm{h} \text {,in }}(\mathrm{k}) \mathrm{Vs}$ pumping power $\left(\mathrm{W}_{\mathrm{p}}\right)$. This is achieved by using the LM algorithm. The training is taking place until the error goal is achieved. Figures 12 to 17 demonstrate the relationship between the training data and the predicted network output after training for $\mathrm{U}$ and $\mathrm{W}_{\mathrm{p}}$ with respect to the inputs $\dot{\mathrm{m}}_{\mathrm{c}}(\mathrm{k}), \dot{\mathrm{m}}_{\mathrm{h}}(\mathrm{k})$ and $\mathrm{T}_{\mathrm{h}}$,in $(\mathrm{k})$. As can be seen from Figs., the error between the training data (target) and the ANN model output is small and the points almost fit except for a few points. This may be improved by several factors such as increasing the number of epochs, increasing learning rate, decreasing goal, etc. The error goal at $1 \mathrm{e}-4$ is attained within 119 and 25 epochs for $\mathrm{U}$ and $\mathrm{W}_{\mathrm{p}}$, respectively. TABLE IV and V show the comparison of experimental data, ANN model output and the relative error (\% error) between the actual values and $\mathrm{NN}$ model output for $\mathrm{U}$ and $\mathrm{W}_{\mathrm{p}}$, respectively. Hence, it is proved that the Neural Network has the ability to predict $U$ and $\mathrm{W}_{\mathrm{p}}$ as a function of $\dot{\mathrm{m}}_{\mathrm{c}}(\mathrm{k}), \dot{\mathrm{m}}_{\mathrm{h}}(\mathrm{k})$ and $\mathrm{T}_{\mathrm{h}, \mathrm{in}}(\mathrm{k})$. However, the \% error, APE and RMSE are found to be more and $\% \mathrm{R}^{2}$ is found to be less (Referring TABLE IV to VI).To improve the above drawbacks, an ANFIS model is proposed in this work.

\subsection{ANFIS Model}

The integration of fuzzy systems and NNs can combine the merits of both systems and offer a more powerful tool for modeling. A neural-fuzzy system is such an integrated system. It uses NNs as tools in fuzzy systems. A neural-fuzzy system, i.e., adaptive network-based fuzzy inference system (ANFIS), is employed in this work as an attempt to develop an adaptive and robust generic model for complex SHE system. In this work, an ANFIS model, proposed by Jang (1993), based on the first order Sugeno fuzzy model has been developed for $\mathrm{U}$ and $\mathrm{W}_{\mathrm{p}}$ in SHE .The NN paradigm is a multilayer feed forward back propagation network. For simplicity, if a fuzzy inference system has two inputs $\mathrm{x}_{1}$ and $\mathrm{x}_{2}$ and one output, $\mathrm{y}$ then a first-order Sugeno fuzzy model, a typical rule set with fuzzy IF-THEN rules can be expressed as

$$
\begin{aligned}
& \text { Rule 1: IF } \mathrm{x}_{1} \text { is } \mathrm{A}_{1} \text {, and } \mathrm{x}_{2} \text { is } \mathrm{A}_{1} \text { THEN } \mathrm{y}_{1}=\mathrm{p}_{1} \mathrm{x}_{1}+\mathrm{q}_{1} \mathrm{x}_{2}+\mathrm{r}_{1} \\
& \text { Rule 2: IF } \mathrm{x}_{1} \text { is } \mathrm{A}_{2} \text { and } \mathrm{x}_{2} \text { is } \mathrm{B}_{2} \text { THEN } \mathrm{y}_{2}=\mathrm{p}_{2} \mathrm{x}_{1}+\mathrm{q}_{2} \mathrm{x}_{2}+\mathrm{r}_{2}
\end{aligned}
$$


The output (y) of the TS fuzzy model is obtained by firing the above rules and applying weighted average defuzzification. The detailed algorithm for ANFIS can be found in the literature (Jang 1993). For practical applications, Jang [7] suggested that the ANFIS algorithm is subjected to some constraints, such as first order Sugeno type system, single output derived by weighted average defuzzification and unity weight of rules. As for a system with multiple outputs, models for each output can be built separately and then combined together to form an overall model [9].The membership functions of the antecedents of the rules as given in equations 5 and 6, the corresponding equivalent ANFIS architecture are shown in Figs. 3 and 4, respectively. The computing flow chart of ANFIS model is shown in Fig.5.The model consists of key components such as inputs and outputs, database and a preprocessor, a fuzzy system generator, a fuzzy inference system and an adaptive NN representing the fuzzy system. The fuzzy inference system generated based on the above procedure for SHE based on the three inputs $\dot{\mathrm{m}}_{\mathrm{c}}(\mathrm{k}), \dot{\mathrm{m}}_{\mathrm{h}}(\mathrm{k})$ and $\mathrm{T}_{\mathrm{h} \text {, in }}(\mathrm{k})$ is shown in Fig.6.The adaptive network can tune the fuzzy system with a backpropagation algorithm based on the collection of input-output data.

This provides the fuzzy system with the ability to learn. It is clear that the network just described can easily be extended to a Sugeno-fuzzy model with multiple inputs and rules. A data base that contains system performance data is a prerequisite for model development. Generally, it is developed by collecting regularly monitored parameters. The quality of the training data base is critical for the model to produce correct information about the system. For the model to describe the system accurately, the data base should contain adequate and correct information on the system. On the other hand, it is common for a raw database to contain some redundant and conflicting data. Thus it is sometimes necessary for the raw training data base to be pretreated to remove redundancies and resolve conflicts in the data. In addition, a more concise training data base will sufficiently reduce the ANFIS training time.

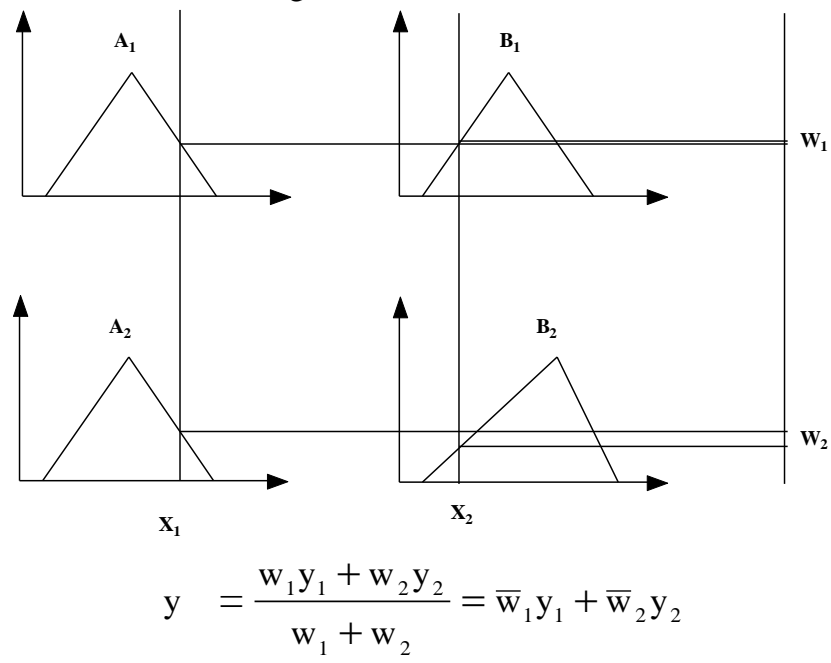

Figure 3. Takagi-Sugeno Fuzzy Model.

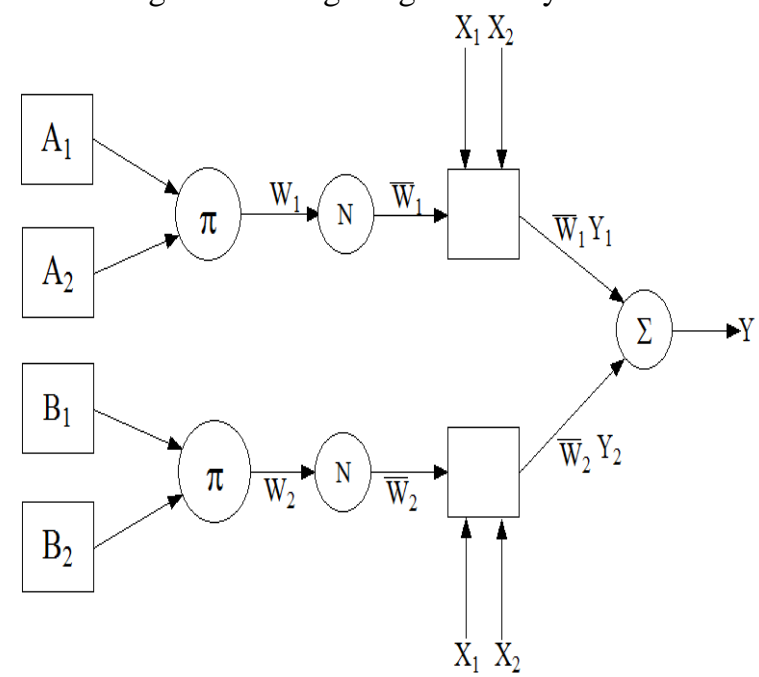

Figure 4. Equivalent ANFIS Model. 


\subsubsection{Implementation of ANFIS Model}

The raw data collected as given in Table III are first transformed into a data file with a specified structure and format using MATLAB software. The quality of the training database (input and output parameters as mentioned in neural model) is important for the model to produce correct information about the system. It is not so easy to manually pretreat the data. A fuzzy clustering method is utilized to automatically carry out this task. As the ANFIS usually starts with a prototype fuzzy system, a fuzzy system generator is needed as given in Figure 5. The fuzzy system generator helps in designing a Sugeno fuzzy system prototype for each output $(\mathrm{U})$ and $\left(\mathrm{W}_{\mathrm{p}}\right)$ from training data. To speed up the process, the automatic generator 'genfis2' is implemented. Once a fuzzy system prototype is available, the ANFIS algorithm will tune and optimize the fuzzy system by learning the training data and finally produce a Sugeno fuzzy system with the same structure as the prototype.

For spiral plate heat exchanger (SHE) two separate fuzzy system have been generated for $\mathrm{U}$ and $\mathrm{W}_{\mathrm{p}}$ as 'FIS U' and 'FIS $\mathrm{W}_{\mathrm{p}}$ ' with same three inputs $\dot{\mathrm{m}}_{\mathrm{c}}$, $\dot{\mathrm{m}}_{\mathrm{h}}$ and $\mathrm{T}_{\mathrm{h} \text {,in }}$ as shown in Fig.6.Thus, the overall computing results is a group of Sugeno fuzzy systems and it is referred to as a resulting ANFIS model.

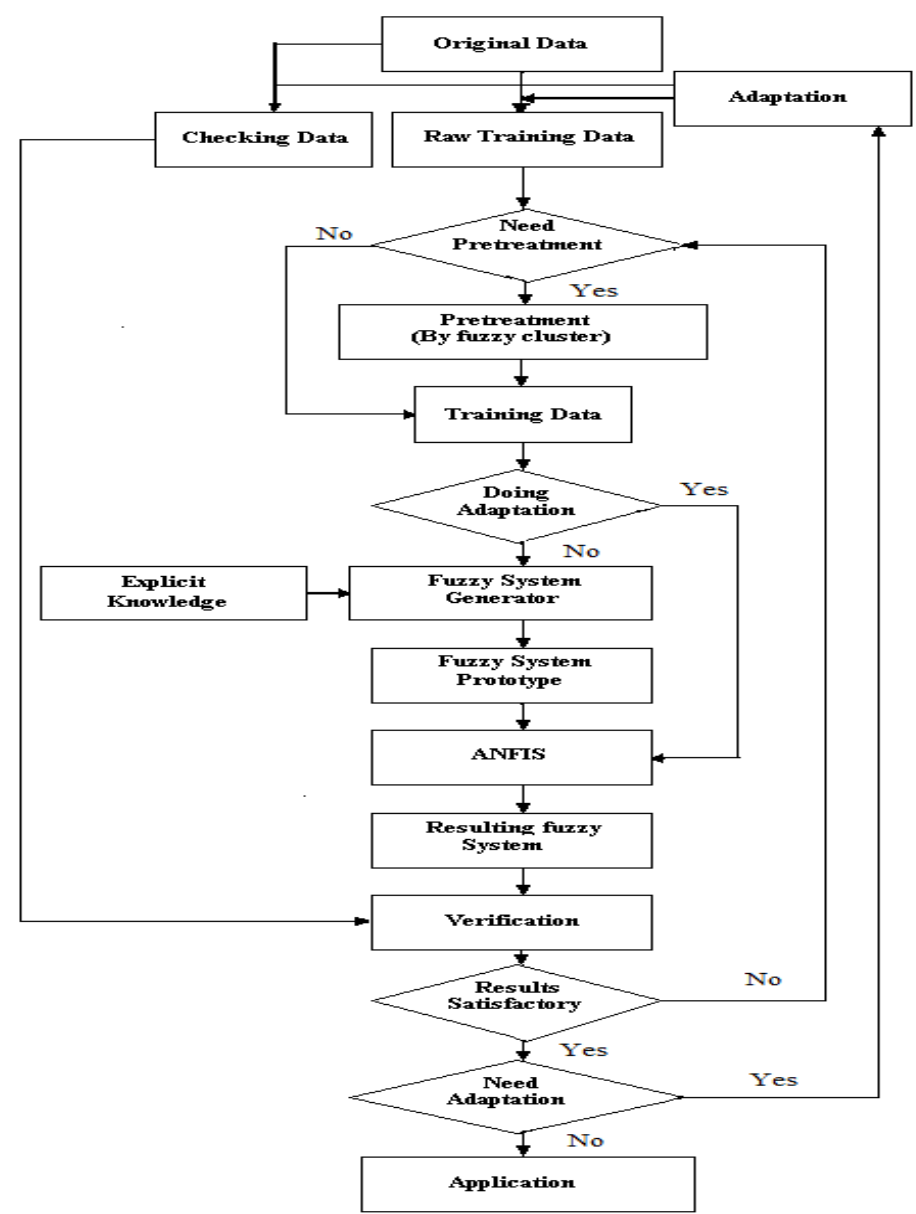

Figure 5. Computing flowchart of ANFIS model.

The input membership functions (MFs) of the inputs were as Gaussian MF.It is defined by:

$$
\operatorname{Gaussian}(\mathrm{x} ; \sigma, c)=\mathrm{e}^{\left\{-[(\mathrm{x}-\mathrm{c}) / \sigma]^{2}\right\}}
$$

where $\mathrm{c}$ and $\sigma$ represents the center and width of the MFs and they are usually called as premise parameters. The variable $\mathrm{x}$ is $\left[\mathrm{x}_{1}, \mathrm{x}_{2}, \mathrm{x}_{3}\right]$ input and they are $\dot{\mathrm{m}}_{\mathrm{c}}, \dot{\mathrm{m}}_{\mathrm{h}}$ and $\mathrm{T}_{\mathrm{h}, \mathrm{in}}$. The MFs of inputs are shown in

Figs.7, 8 and 9.Each has three labels Low, Medium and High. 


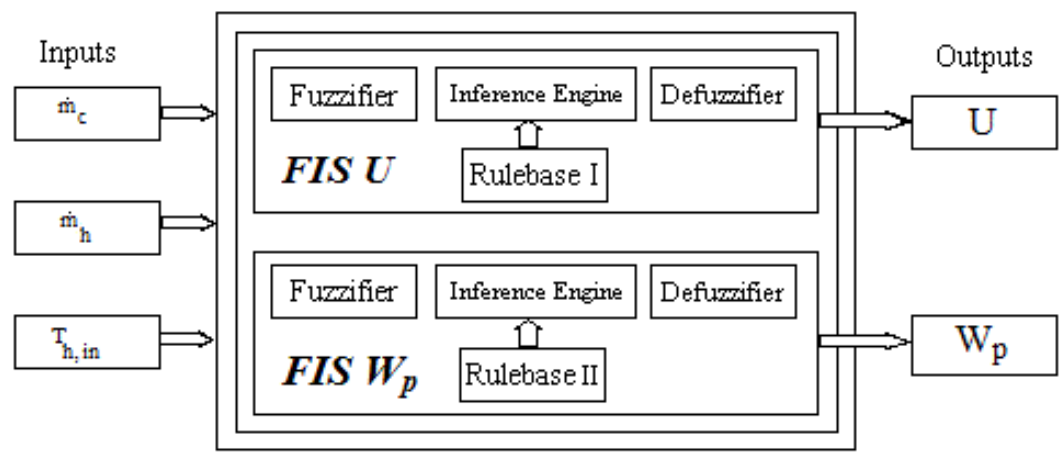

Sugeno Fuzzy Systems

Figure 6. Structure of resulting Fuzzy model of SHE.

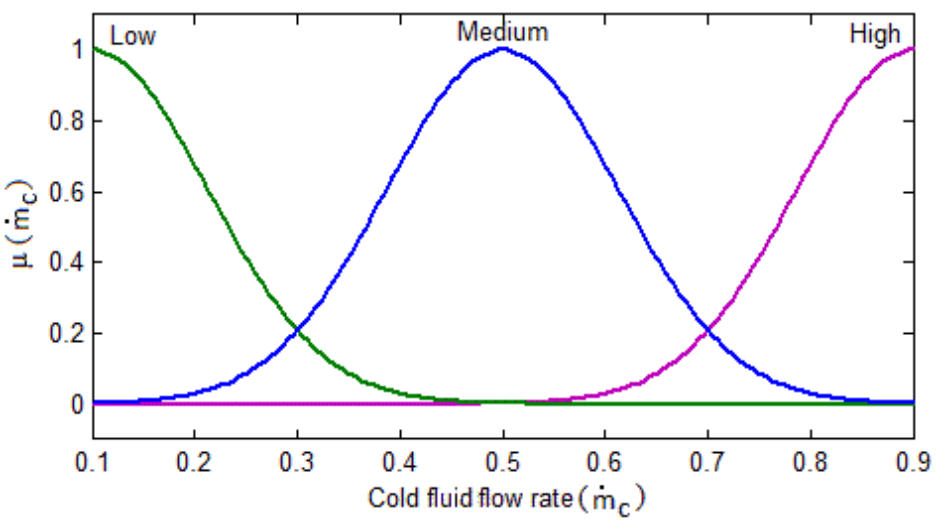

Figure 7.Membership functions of cold fluid flow rate.

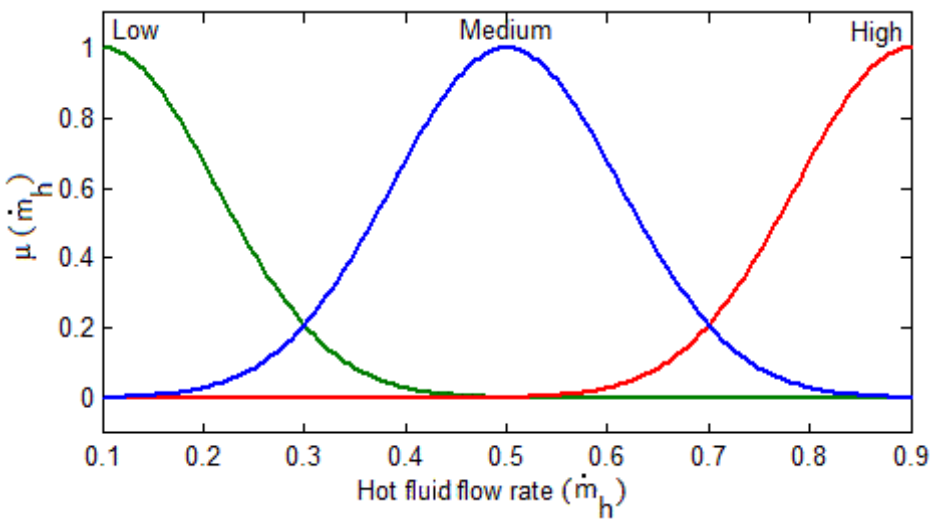

Figure 8.Membership functions of hot fluid flow rate.

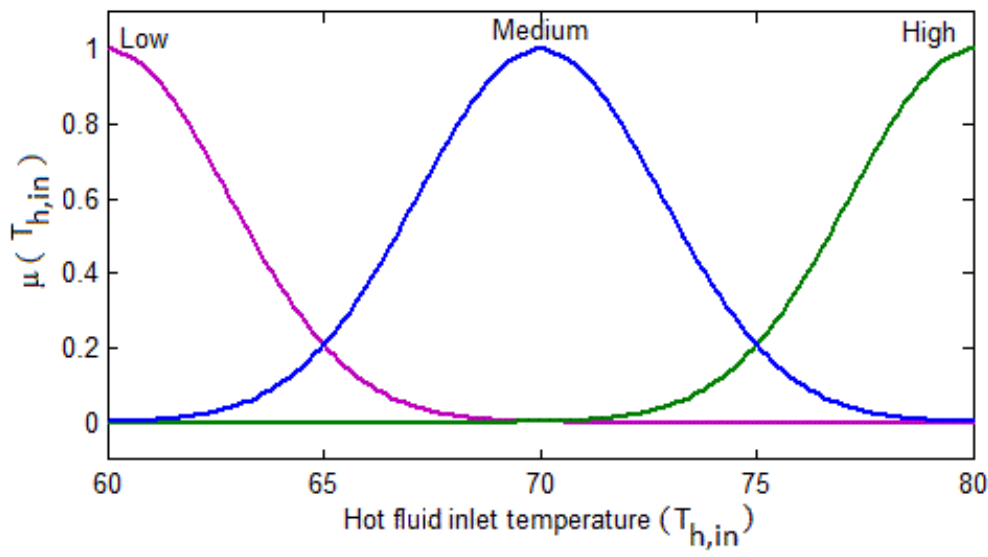

Figure 9.Membership functions of hot fluid inlet temperature. 
The output membership functions of outputs were specified by the following equation:

$$
\mathrm{f}(\mathrm{x} ; \mathrm{a}, \mathrm{r})=\mathrm{a} . \mathrm{x}+\mathrm{r}
$$

where $\mathrm{a}=\left[\mathrm{a}_{1}, \mathrm{a}_{2}\right.$ and $\left.\mathrm{a}_{3}\right]$ and $\mathrm{r}$ is constant. The variables $\{\mathrm{a}, \mathrm{r}\}$ are called consequent parameters that are trained along with the premise parameters $\{\sigma, c\}$ by the model building process as shown in Fig.5.The Root Mean Squared Error (RMSE) obtained by ANFIS model for $\mathrm{U}$ and $\mathrm{W}_{\mathrm{p}}$ are shown in Figs. 10 and 11,respectively.

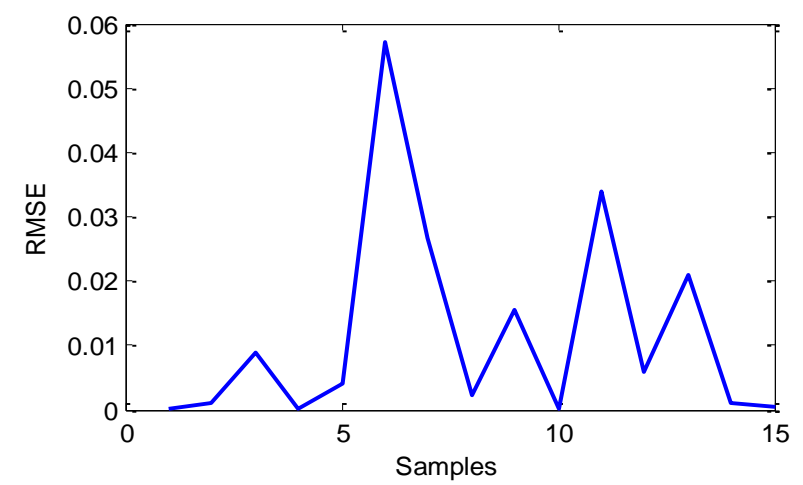

Figure 10.Root mean squared error (RMSE) for heat transfer coefficient (U).

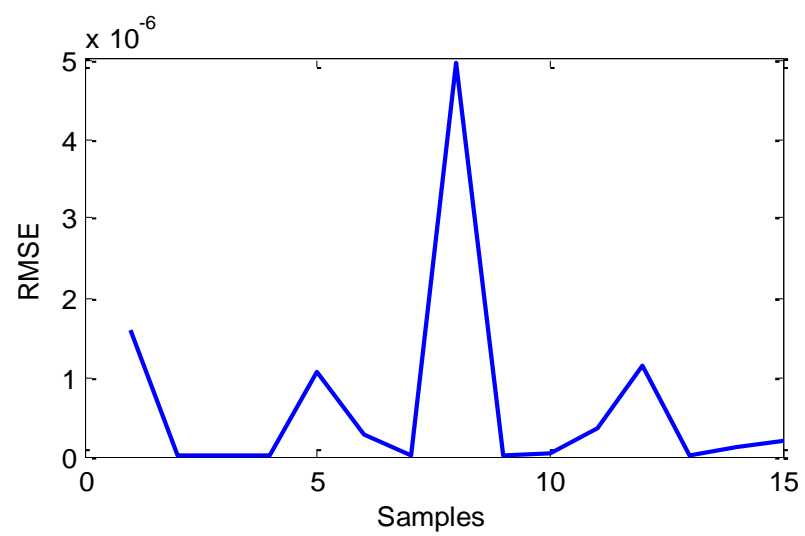

Figure 11.Root mean squared error (RMSE) for pumping power $\left(\mathrm{W}_{\mathrm{p}}\right)$.

\section{Results and Discussion}

The performances of spiral plate heat exchanger were assessed for $\mathrm{U}$ and $\mathrm{Wp}$ by evaluating the scatter between the experimental readings and the predicted outputs obtained by ANN and ANFIS models via root mean square error (RMSE), average percentage error (APE) and correlation coefficients $\left(\mathrm{R}^{2}\right)$ [7].They are calculated as follows:

$$
\begin{aligned}
\text { RMSE } & =\sqrt{\left(\frac{1}{N}\right) \sum\left(\mathrm{t}_{\mathrm{j}}-\mathrm{O}_{\mathrm{j}}\right)^{2}} \\
\mathrm{R}^{2}=1-\left[\frac{\sum\left(\mathrm{t}_{\mathrm{j}}-\mathrm{O}_{\mathrm{j}}\right)^{2}}{\sum\left(\mathrm{t}_{\mathrm{j}}\right)^{2}}\right]^{\frac{1}{2}} & \mathrm{APE}=\frac{1}{\mathrm{~N}} \sum_{i=1}^{N} \frac{n \operatorname{norm}\left(\mathrm{t}_{\mathrm{j}}-\mathrm{O}_{\mathrm{j}}\right)}{\mathrm{t}_{\mathrm{j}}} \times 100
\end{aligned}
$$

where $t_{j}$ and $\mathrm{O}_{j}$ are $\mathrm{j}^{\text {th }}$ target and output value. The ANN and ANFIS model output for $\mathrm{U}$ are compared with the experimental values for various inputs like $\dot{\mathrm{m}}_{\mathrm{c}}, \dot{\mathrm{m}}_{\mathrm{h}}$ and $\mathrm{T}_{\mathrm{h} \text {, in }}$ and are shown in Figures 12, 13 and 14, respectively. From all these results, it is observed that ANFIS model output almost fit with the experimental results. But ANN model output does not match with all points. The corresponding \% error calculated for ANN 
and ANFIS models are tabulated in Table IV. Similarly the ANN and ANFIS model output for $\mathrm{W}_{\mathrm{p}}$ are compared with the experimental values for various inputs like $\dot{\mathrm{m}}_{\mathrm{c}}, \dot{\mathrm{m}}_{\mathrm{h}}$ and $\mathrm{T}_{\mathrm{h} \text {, in }}$ and are shown in Figures 15, 16 and 17, respectively. From all these results, it observed once again that ANFIS model output almost fit with the experimental results. But ANN model output does not match with all the points.

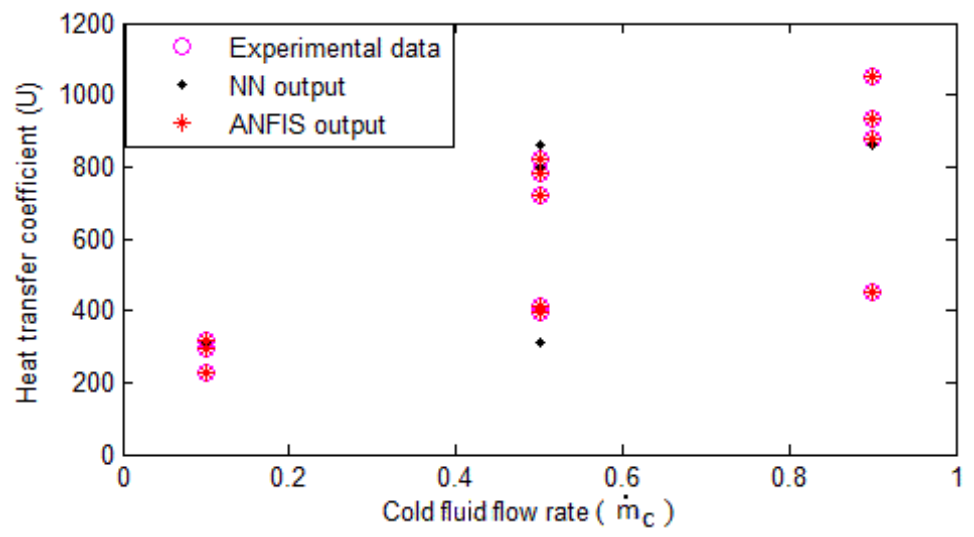

Figure 12.Experimental and predicted values of U Vs $\dot{m}_{c}$.

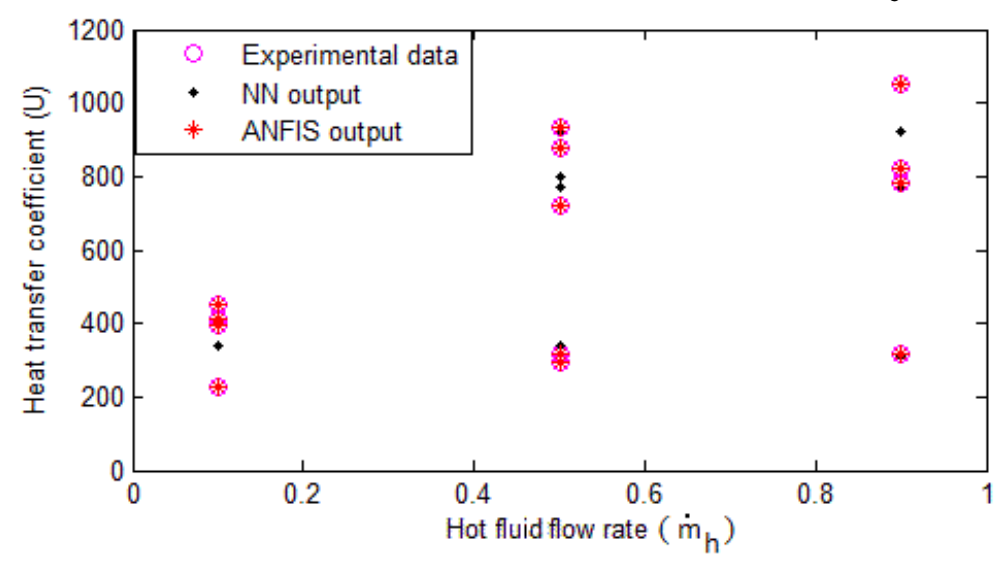

Figure 13.Experimental and predicted values of U Vs $\dot{m}_{h}$.

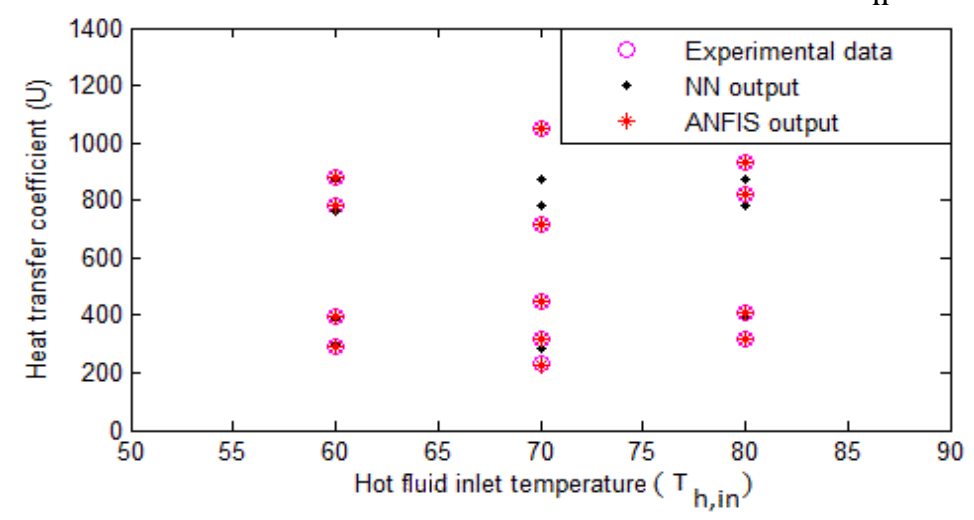

Figure 14.Experimental and predicted values of $U V_{s} T_{h \text {,in }}$. 
TABLE V. Experimental readings and models output of $U$ for water-methanol system.

\begin{tabular}{|c|c|c|c|c|}
\hline \multicolumn{2}{|c|}{ Overall heat transfer coefficient (U) } & \multicolumn{2}{c|}{ \% Error } \\
\hline Experimental & NN model output & ANFIS model output & NN model & ANFIS model \\
\hline 719 & 735 & 719 & -2.2253 & 0 \\
\hline 719 & 735 & 719 & -2.2253 & 0 \\
\hline 316 & 316 & 316 & 0 & 0 \\
\hline 292 & 265 & 292 & 9.2 & 0 \\
\hline 1050 & 1000 & 1050 & 4.7619 & 0 \\
\hline 819 & 819 & 818 & 0 & 0.1221 \\
\hline 397 & 396 & 396 & 0.2519 & 0.2519 \\
\hline 933 & 907 & 933 & 2.7867 & 0 \\
\hline 229 & 235 & 228 & -2.6201 & 0.4367 \\
\hline 781 & 780 & 781 & 0.1280 & 0 \\
\hline 411 & 411 & 410 & 0 & 0.2433 \\
\hline 880 & 905 & 880 & -2.8409 & 0 \\
\hline 318 & 318 & 317 & 0 & 0.3145 \\
\hline 451 & 501 & 451 & -11.0865 & 0 \\
\hline 719 & 735 & 719 & -2.2253 & 0 \\
\hline
\end{tabular}

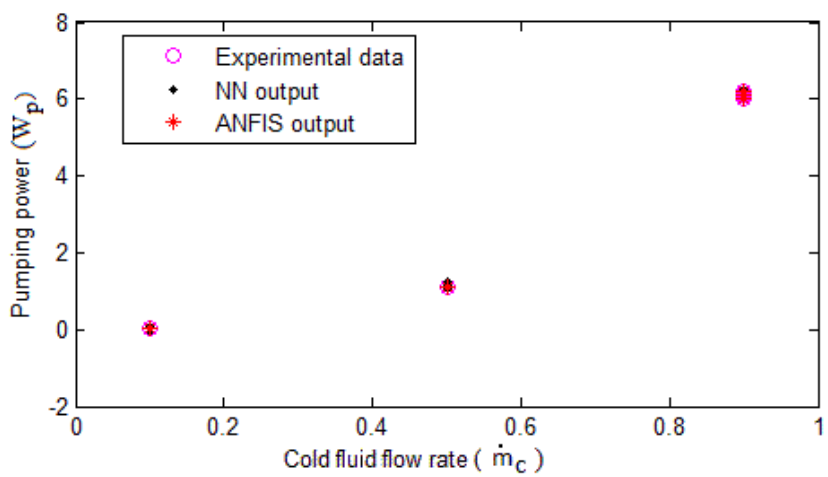

Figure 15.Experimental and predicted values of $\mathrm{W}_{\mathrm{p}} \mathrm{Vs} \dot{\mathrm{m}}$.

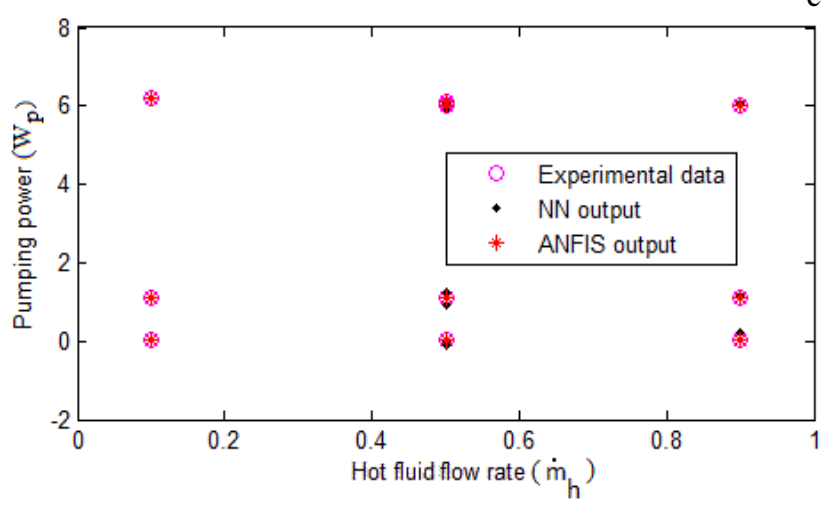

Figure 16.Experimental and predicted values of $\mathrm{W}_{\mathrm{p}} \mathrm{Vs} \dot{\mathrm{m}}_{\mathrm{h}}$

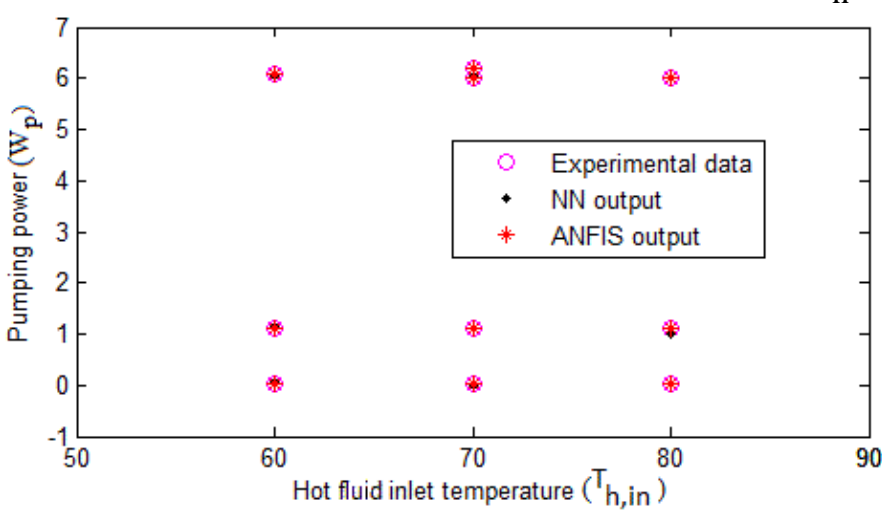

Figure 17.Experimental and predicted values of $\mathrm{W}_{\mathrm{p}} \mathrm{Vs}_{\mathrm{h}} \mathrm{T}_{\mathrm{h} \text {, in }}$ 


\section{Conclusion}

In this paper, ANN and ANFIS models have been developed for the prediction of heat transfer coefficient (U) and pumping power $\left(\mathrm{W}_{\mathrm{p}}\right)$ as a function of $\dot{\mathrm{m}}_{\mathrm{c}}, \dot{\mathrm{m}}_{\mathrm{h}}$ and $\mathrm{T}_{\mathrm{h}, \text { in }}$ with good degree of accuracy.

The experimental data obtained based on RSM were used to develop the models. However from the simulation results and the performance Tables IV to VI, it is observed that the ANFIS models have high prediction performance with less relative error, RMSE, APE and large $\% \mathrm{R}^{2}$ when compared to ANN models. The ANN model produces maximum \% error of -11.0865 and -12 for $\mathrm{U}$ and $\mathrm{W}_{\mathrm{p}}$ when compared to ANFIS model (Referring to Table IV and $\mathrm{V}$ ), which produces 0.3145 and 1.0 only for $\mathrm{U}$ and $\mathrm{W}_{\mathrm{p}}$. Also, the ANN model produces more RMSE (26.2755) value and less \% $\mathrm{R}^{2}$ (85.84) value for $\mathrm{U}$ and also the ANN model produces more APE value (-11.0381) and less $\% \mathrm{R}^{2}(82.3876)$ for $\mathrm{W}_{\mathrm{p}}$, when compared to ANFIS model (Referring to Table VI). Therefore, ANFIS model can be used as a modeling tool for the performance analysis of SHE.

TABLE VI. Experimental readings and model outputs of Wp for water-methanol system.

\begin{tabular}{|c|c|c|c|c|}
\hline \multicolumn{2}{|c|}{ Pumping power( $\left.\mathbf{W}_{\mathbf{p}}\right)$} & \multicolumn{2}{c|}{ \%Error } \\
\hline Experimental & NN model output & ANFIS model output & NN model & ANFIS model \\
\hline 1.13 & 1.1059 & 1.13 & 2.1327 & 0 \\
\hline 1.13 & 1.1186 & 1.129 & 1.0088 & 0.0885 \\
\hline 0.01 & 0.011 & 0.0099 & -10.0000 & 1.0000 \\
\hline 0.02 & 0.0187 & 0.02 & 6.5000 & 0 \\
\hline 6.01 & 6.0795 & 6.01 & -1.1564 & 0 \\
\hline 1.13 & 1.0975 & 1.129 & 2.8761 & 0.0885 \\
\hline 1.10 & 1.1970 & 1.09 & -8.8182 & 0.9091 \\
\hline 6.02 & 6.0784 & 6.02 & -0.9701 & 0 \\
\hline 0.02 & 0.0187 & 0.02 & 6.5000 & 0 \\
\hline 1.13 & 1.1619 & 1.129 & -2.8230 & 0.0885 \\
\hline 1.11 & 1.0645 & 1.11 & 4.0991 & 0 \\
\hline 6.10 & 6.0815 & 6.09 & 0.3033 & 0.1639 \\
\hline 0.01 & 0.012 & 0.0099 & -12.0000 & 1.0000 \\
\hline 6.20 & 6.0800 & 6.19 & 1.9355 & 0.1613 \\
\hline 1.13 & 1.1770 & 1.13 & -4.1593 & 0 \\
\hline
\end{tabular}

TABLE VI. Performance Measures of ANN and ANFIS models.

\begin{tabular}{|c|c|c|c|c|}
\hline \multirow{2}{*}{ Model } & \multicolumn{3}{c|}{ Performance Measures } \\
\cline { 3 - 6 } & $\mathbf{U}$ & $\mathbf{R M S E}$ & $\mathbf{A P E}$ & \% $^{\mathbf{2}}$ \\
\hline \multirow{2}{*}{ ANN } & $\mathbf{W}_{\mathrm{p}}$ & 0.2755 & 0.2817 & 85.8464 \\
\hline \multirow{3}{*}{ ANFIS } & $\mathbf{U}$ & 0.5774 & -11.0381 & 82.3876 \\
\cline { 2 - 5 } & $\mathbf{W}_{\mathrm{p}}$ & 0.0045 & 0.0912 & 99.68 \\
\hline
\end{tabular}

\section{References}

[1] Holger Martin, Heat exchangers (Hemisphere Publishing Corporation, London, 1992).

[2] Rangasamy Rajavel and Kaliannagounder Saravanan, Heat transfer studies on spiral plate heat exchanger, Journal of Thermal Science, 12(3), 2008, 85-90.

[3] R.Rajavel and K. Saravanan, An experimental study on spiral plate heat exchanger for electrolytes, Journal of the University of Chemical Technology and Metallurgy,43(2),2008, 255-260.

[4] K.S.Manoharan and K. Saravanan, Experimental studies in a spiral plate heat exchanger, European Journal of Scientific Research, 75(2), 2012, 157-162.

[5] S.A.Mandavgane and S.L.Pandharipande,Application of optimum ANN architecture for heat exchanger modeling, Indian Journal of Chemical Technology,13,2006,634-639.

[6] A.R.Moghadassi, S.M.Hosseini, F.Parvizian, F.Mohamadiyon, A.Behzadi Moghadam and A. Sanaeirad, An expert model for the shell and tube heat exchangers analysis by Artificial Neural Networks, ARPN Journal of Engineering and Applied Sciences, 6(9), 2011,78-93.

[7] R.Ramkumar and A.Ragupathy,Optimization of operating parameters evaluation of forced draft cooling tower using Response Surface Methodology (RSM) And Artificial Neural Networks, Journal of Mechanical Science and Technology,26(5), 2012,1643-1650.

[8] Jyh-Shing Roger Jang, ANFIS : Adaptive-Network- Based Fuzzy Inference System, IEEE Transactions on Systems, Man and Cybernetics, 23(3), May/June 1993.

[9] Joo-Hwa Tay and Xiyue Zhang, Neural Fuzzy modeling of anaerobic biological wastewater treatment systems, Journal of Environmental Engineering, 1999, 1149-1159.

[10] P.Mullai,S.Arulselvi, Huu-Hao Ngo and PL.Sabarathinam, Experiments and ANFIS modelling for the biodegradation of Penicillin$\mathrm{G}$ wastewater using anaerobic hybrid reactor, Journal of Bioresource Technology, Elsevier,102, 2011,5492-5497.

[11] M.Rajasimman and K.Murugaiyan, Application of the statistical design for the sorption of lead by hypnea valentiae, Journal of Advanced Chemical Engineering, Ashdin Publishing,2,1-7,2012. 